\title{
Molybdates and tungstates sorption on organo-smectites as a process controlled by the type and amount of surfactant
}

\author{
Barbara Muir, Damian Andrunik, Tomasz Bajda \\ AGH University of Science and Technology, Faculty of Geology, Geophysics and Environmental \\ Protection; al. A. Mickiewicza 30,30-059 Krakow, Poland; e-mail: basia.muir@gmail.com
}

(C) 2016 Authors. This is an open access publication, which can be used, distributed and reproduced in any medium according to the Creative Commons CC-BY 4.0 License requiring that the original work has been properly cited.

Modification of a smectite with organic surfactants leads to the formation of an organo-mineral complex characterized by a positive charged (Bajda et al. 2015). The process involves the exchange of naturally occurring cations, e.g. $\mathrm{Ca}^{2+}$, $\mathrm{Mg}^{2+}, \mathrm{Na}^{+}, \mathrm{K}^{+}$by large organic cations of surfactants. This alteration makes it possible to use organo-smectites as sorbents to remove anionic forms of $\mathrm{Mo}(\mathrm{VI})$ and $\mathrm{W}(\mathrm{VI})$ from aqueous solutions. The concentration of molybdenum in the environment is significantly enhanced by anthropogenic inputs from coal-resource development, fly ash, sewage sludge and hard-rock mining activity (Kalembkiewicz \& Sočo 2009). W(VI) is released to the environment through its use in winter tires or by its applications in industry e.g. enriches alloys or electrotechnics (Gustafsson 2003).

The environmental behavior of molybdenum and tungsten becomes very complex once they dissolve as $\mathrm{Mo}(\mathrm{VI})$ and $\mathrm{W}(\mathrm{VI})$ anions occur as a monomer only in alkaline or neutral solutions. Bentonite from the Jelšovy Potok in Slovakia, rich in montmorillonite phase, was used in the sorption experiments (Bajda et al. 2015). Through the preparation of a series of experiments it was possible to define the impact of various surfactants, their amount and organo-smectites' properties order on the sorption capacity and $\mathrm{pH}$ effect. Smectite has been modified with dodecyltrimethylammonium bromide (DDTMA), didodecyldimethylammonium bromide (DDDDMA), hexa- decyltrimethylammonium bromide (HDTMA) and dihexadecyldimethylammonium bromide (DHDDMA) in amounts of: 0.5, 1.0 and 2.0 of cation exchange capacity (CEC). Experiments of $\mathrm{Mo}(\mathrm{VI})$ and $\mathrm{W}(\mathrm{VI})$ sorption on organo-smectites were conducted under various concentrations of $\mathrm{Mo}(\mathrm{VI})$ and $\mathrm{W}(\mathrm{VI})(0-20 \mathrm{mM})$ and in wide range of $\mathrm{pH}$ 's (1-13). The effectiveness of modifications follows the order DDTMA-smectite > HDTMA-smectite > DDDDMA-smectite $>$ DHDDMA-smectite. The unmodified smectite did not remove $\mathrm{Mo}(\mathrm{VI})$ and $\mathrm{W}(\mathrm{VI})$ anions from the aqueous solution at all. In the removal of $\mathrm{Mo}(\mathrm{VI})$, sorption efficiency follows the order: DDTMA-smectite > DDDDMA-smectite $>$ HDTMA-smectite > DHDDMA-smectite. In case of $\mathrm{W}(\mathrm{VI})$ the efficiency of the removal can be place: DDDDMA-smectite > DDTMA-smectite > HDTMA-smectite > DHDDMA-smectite. With an increasing concentration of $\mathrm{Mo}(\mathrm{VI})$ or $\mathrm{W}(\mathrm{VI})$ in the solutions, the sorption increases. The maximum sorption capacity in the removal of $\mathrm{Mo}(\mathrm{VI})$ was $1710 \mathrm{mmol}$ $\mathrm{Mo}(\mathrm{VI}) / \mathrm{kg}$ in case of smectite modified with DDTMA at 0.5 CEC.

The best result of tungsten sorption was $5882 \mathrm{mmol} \mathrm{W}(\mathrm{VI}) / \mathrm{kg}$ and it was obtained for DDDDMA-smectite (0.5 CEC). Results showed that the sorption is more effective at a lower $\mathrm{pH}$, in both $\mathrm{Mo}(\mathrm{VI})$ and $\mathrm{W}(\mathrm{VI})$ removal. The smectite modified with surfactant with double carbon 
chain (DDDDMA, DHDDMA) proved to be a better sorbent. With an increasing amount of surfactant attached to the smectite, the sorption efficiency increases.

We gratefully acknowledge the support of The $\mathrm{Na}$ tional Science Center, Poland (NCN) having provided grant number 2014/13/N/ST10/04945.

\section{REFERENCES}

Bajda T., Szala B. \& Solecka U., 2015. Removal of lead and phosphate ions from aqueous solutions by organo-smectite. Environmental Technology, 36, 2872-2883.

Gustafsson J.P., 2003. Modelling molybdate and tungstate adsorption on ferrihydrite. Chemical Geology, 200, 105-115.

Kalembkiewicz J. \& Sočo E., 2009. Industrial fly ash as a potential source of molybdenum and emission. Ochrona Środowiska i Zasobów Naturalnych, 40, 601-607. 